\title{
Production of motor biofuels in the context of environmental management of the oil industry
}

\author{
Iuner Kapkaev ${ }^{1, *}$, Ivan Dobrovolsky ${ }^{1}$, Dmitry Sorokin ${ }^{1}$ \\ ${ }^{1}$ Chelyabinsk State University, Br. Kashirinyh, 129, Chelabinsk, 454001, Russia
}

\begin{abstract}
The paper deals with the current state and problems of the Russian and World fuel and energy complex. Special attention is paid to the prospects for the development of alternative energy and the search for real opportunities to limit the monopoly power of oil producing and refining companies, which is a promising economic and technological task. The relevance of the paper is determined by the importance of solving the issues of searching for alternatives to hydrocarbon fuel in domestic and industrial use, especially for the Russian economy, for which the oilproducing and refining sector is not only a driver of economic development, but also a strategic lever for the implementation of geopolitical interests. In this regard, the paper considers the existing methods and suggests the approach to the use of biofuels as cheap and affordable raw materials for the development of alternative energy.
\end{abstract}

\section{Introduction}

The new economic era that began after the financial crisis of 2008-2009, foreshadowed the beginning of the "sunset" of a consumption economy that is slowing economic growth due to population ageing, this became particularly evident in respect of the restrictive measures adopted by all countries of the World because of the pandemic, the new virus. Government attempts to stimulate economic activity in most countries are reduced to conducting an ultra-soft monetary policy, as a result of which the engine of global economic growth is primarily developing countries, such as China and India, whose economies, although they are an interesting investment product, investments in them have a lot of macroeconomic risks, including those associated with the lack of confidence of experts in their ability to maintain the same high rates of economic growth. Given the challenges facing the world economy, it is clear that forecasting future prices for oil and petroleum products is an extremely difficult task, especially in the context of the current macroeconomic confrontation within OPEC + . The main trends in the development of the market of hydrocarbons and their derivatives today are the following.

First, the growth and development of the Asian economic segment leads to an increase in the middle class in the developing countries of Asia, which will contribute to the growth of the global fleet, and consequently, the growth of demand for petroleum products [1].

Secondly, despite the fact that traditional cars with an internal combustion engine occupy a dominant position in the structure of the fleet, but the increase in the share of

*Corresponding author: zam@csu.ru 
electric vehicles is a factor in restraining the growth of fuel prices. Especially active research in this direction is carried out by countries that are traditionally adherents of the "green" lifestyle, such as Iceland [2]. It is important in this trend that the countries recognized by the World community as traditionally the most harmful to the environment China and India, are also developing measures to smooth their impact on the environment [1].

Third, the largest contribution to the increase in oil consumption by road transport is made by cargo transportation, and therefore, with the business logistics unchanged, this causes a growing demand for oil when the production of "old"” fields falls and allows us to predict the potential insufficiency of oil volumes with low production costs to cover the deficit [3].

Fourth, in the medium term, excess production capacity in the global refining industry will persist, which will continue to have a negative impact on profitability in the industry, especially in the European market of petroleum products, which will be exacerbated by the growth of light oil products in the Middle East, Asia-Pacific and Russia. However, there have been changes in this aspect, in particular, the UAE has begun to actively explore the development of renewable energy [4].

Fifth, Russian oil production has good growth prospects, but there is a reduction in consumption of motor fuels due to the difficulties of developing the industrial sector, the negative effect of the tax maneuver, which has significantly worsened the economy of oil refining, as well as a critical level of tax burden, which can lead to a deficit in the market of gasoline and a sharp increase in fuel prices in the country. It should be noted that this trend has overtaken the Russian economy with a two-year delay, and the need to solve the problems of supplying the aviation industry through the development of alternative energy sources has been solved by scientists for a long time $[5,6]$.

In the current conditions, it is quite natural to consider the development of alternative energy as a search for real opportunities to limit the monopoly power of oil producing and refining companies, which is a promising economic and technological task not only for the State, citizens, and the economy, but also for the participants of the oil sector themselves offering its main participants ways to diversify. This may be the reason for the research of scientists in the direction of renewable energy sources in the traditionally "oil" countries of the Middle East [7, 8]. This is particularly relevant because pricing in the global hydrocarbon market is significantly influenced not so much by economic as by political motives, which for their implementation cloaked by economic and financial reasons and use mechanisms of price collusion. In the current conditions, to increase national economic independence and stability, it is necessary to introduce and expand the use of alternative sources for fuel production, one of which is biofuels obtained from waste production, including agricultural [9]. This simultaneously solves several problems and, in addition to the main one - resource substitution, allows us to dispose of most of the industrial wastes without causing direct harm to the environment, which fruitfully affects the quality of life and most of the economic and demographic indicators of the region's development [10].

The purpose of the paper is to study the production efficiency and technological viability of existing methods for obtaining biofuels for alternative energy needs without the use of hydrocarbons, as well as to develop proposals for their modernization to improve economic indicators. In order to achieve this goal, we consider the options already existing in Russian practice for obtaining biofuels, sometimes unfairly forgotten and existing only in the form of patent research, it also provides opportunities for their practical implementation with using the most technically simple and financially affordable method of implementation. To date, the most resource-efficient and energy-saving method of processing industrial waste into biofuels is the method of processing organic raw materials with the help of microorganisms. It partially solves the problem of expanding the range of 
raw materials for biofuels production, increasing the yield of the product while improving its quality indicators. This method of processing can be effectively used in the agroindustrial complex and in public utilities.

\section{Data and methodology}

Due to the constant rise in price of energy increases the relevance of biofuels production, especially for the development of the so-called low energy of agro-industrial complex of Russia, including overcoming of its negative impact on the environment that have long been studied in various countries $[11,12]$. Synthetic liquid fuel is a complex mixture of hydrocarbons obtained from raw materials of non-petroleum origin. The problem of synthetic fuel production arose at the beginning of the 20th century due to the lack of significant oil fields in many industrialized countries or regions, later - with limited oil reserves at a continuously growing scope of its consumption, and currently due to a number of geopolitical contradictions. The scope of introduction of thermal processing of raw materials, their liquefaction or gasification depends on many factors, including the degree of intensification of the processes themselves, the degree of depletion of oil reserves and prices for it and natural gas. According to technical and economic calculations and forecasts, the cost of producing synthetic liquid fuels, for example, by coal liquefaction methods, is determined by the value of about $\$ 46 /$ barrel, high-calorie gas (in terms of oil, $\$$ $49.3 /$ barrel) with a possible reduction to $\$ 31 /$ barrel when implementing a new generation of technological processes. Currently, at this cost, the production of synthetic liquid fuel by classical methods is possible only if there is no access to oil resources at all, in addition, the resulting product has a number of disadvantages.

Therefore, for agricultural producers, as well as private personal and industrial consumption, it is possible to obtain biofuels from more accessible plant resources: wood (wood waste, peat, leaves), waste of life (household waste, including lignin), agricultural waste (chicken droppings, stems, tops), specially grown high-yielding crops and plants. Thermochemical technologies are most effective for using dry biomass (incineration, gasification, pyrolysis). For wet biomass - biochemical processing technologies are most affective with produce biogas (decomposition of organic raw materials) or liquid biofuels (fermentation) $[13,14]$. The use of these raw materials will significantly reduce the cost of the synthetic liquid fuel production process, increasing its profitability and making it comparable to oil production even in conditions of price confrontation and dumping.

The disadvantage of plant raw materials, in such conditions, can only be its limitations, which can be overcome, for example, by expanding the area of sowing new high-yielding varieties of plants. Thus, the created most productive sorghum variety Sever-5 allows us to get biomass from 37 to $110 \mathrm{t} / \mathrm{ha}$. With an average yield of this variety of $60 \mathrm{t} / \mathrm{ha}$, we can get $4 \mathrm{t} /$ ha of ethanol. Much attention is paid to the production of rapeseed of biofuels. However, the cultivation of these plants requires the use of significant areas with highquality soils, mainly in the southern regions of Russia, which is costly and irrational. At the moment, the following methods of obtaining synthetic liquid fuel are known and used in practice.

The first method is the processing of coal using microorganisms with produce biogas, which is processed in an open flow system where microorganisms are cultivated. The complexity of using this method of obtaining biofuels is due to the multi-stage conversion of coal and the limited availability of the raw materials used for most small agricultural enterprises (Register of intellectual industrial property No 2248398). Also, the disadvantages of this method include the duration and complexity of adaptation to coal-peat environments of bacterial culture, a relatively low yield of biofuels from non-coal raw materials, as well as the significant presence of toxic phenol in the liquid fraction. The 
complexity of adaptation of microorganisms is mainly due to the content of methane or gasoline components in coal, the formation of which requires a high consumption of carbon dioxide, and the formation of phenol, cresol, solid paraffins that are not of interest as biofuels, the need for carbon. These restrictions significantly restrict its widespread use.

The second method - is a microbiological method for obtaining hydrocarbon fractions from crushed raw materials using the bacteria Thiobacillus aquaesulis and Thiobacillus thioparus, etc. (Register of intellectual industrial property No 2180919). In the same way, a valuable petrochemical substance is obtained: gasoline and diesel fractions, fuel oil, etc. The raw materials are humins, stone and brown coals, peat, and hydrogen donors can be phenol, cresol. The maximum yield of products is $90 \%$ of the mass of raw materials. In this regard, for the production of biofuels, agro-industrial enterprises use plant raw materials, increasing the yield of biofuels and its quality by reducing the yield of sulfur, phenol and increasing the content of hydrocarbons with a high octane number, partially overcoming the main disadvantages associated with its use (see table 1).

Table 1. Advantages and disadvantages of biofuels in comparison with oil.

\begin{tabular}{|c|c|}
\hline Advantages & Disadvantages \\
\hline Environmental significance - public good & Consumer properties (reduced \\
(Reducing carbon monoxide emissions by half) & engine power) \\
\hline $\begin{array}{c}\text { Environmental significance }- \text { public good } \\
\text { (Biodegradable, non-toxic, no sulfur) }\end{array}$ & $\begin{array}{c}\text { Consumer properties (Increased } \\
\text { fuel consumption) }\end{array}$ \\
\hline
\end{tabular}

Thus, these methods, despite their advantages and consumer interest have disadvantages that hinder their widespread use. First, the duration of the process and the complexity of adaptation to wood and peat waste bacteria, there is a relatively low yield of biofuels from non-coal raw materials, for example, 1 ton of peat receive $200 \mathrm{~kg}$ of broad fraction of hydrocarbons $(20 \%)$, than in the liquid fraction up to $20 \%$ may be the content of highly toxic phenol. Secondly, the decrease in the output of methane and gasoline components of products, which is due to the formation and emission of carbon dioxide, increased carbon consumption for the formation of phenols, cresol, solid paraffins, which significantly reduce the quality of biofuels.

Third, the lack of technical solutions for the use of the above products not only hinders the expansion of the use of this method, but also reduces the efficiency of the process. Fourth, there is a complex technological scheme for processing various waste compositions, which requires the use of a variety of chemically resistant and high-performance equipment and mechanisms, especially for preparing waste for use. The technological scheme of production is shown in figure 1.

The flowchart shows the stages of the process and equipment for obtaining bioethanol from wheat flour, which is applicable for the production of biofuels and other raw materials. All this makes them not yet a complete alternative to the classic oil fuel, but only an additional option that expands the capabilities of consumers, mainly small ones, in terms of obtaining fuel in the absence or difficulty of conventional methods of supply. 


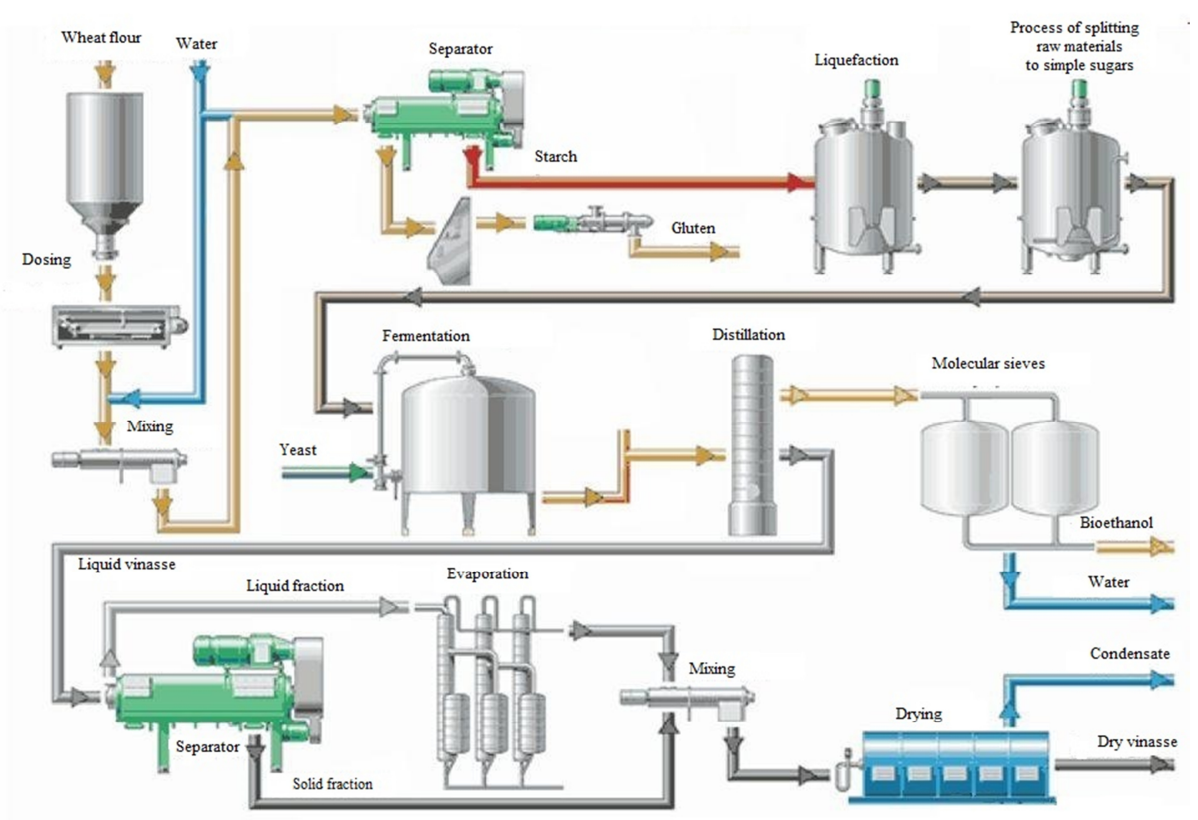

Fig. 1. Principal diagram of bioethanol production.

\section{Results}

The technical solution to the problem is that a method for obtaining biofuels is proposed, including the processing of crushed row material by microorganisms in the presence of compounds that are hydrogen donors, characterized in that the raw material is used as a plant eichornia and its mixtures with peat, lignin and fermented manure, animal stomach contents, active digester sludge, which include methanogenic microorganisms with a culture medium based on a phosphate-chloride-carbonate buffer, as well as catalysts for the intensification of the biogas extraction process in the form of wood processing waste containing humates and cellulose and / or sugar production waste. In addition the process is carried out at a temperature from 15 to $70^{\circ} \mathrm{C}$ in anaerobic or aerobic conditions, synthesized methane is selected, and the resulting carbon dioxide is left in the reactor, to which hydrogen donors, humic compounds, microorganisms of the species Thiobacillus aquaesulis and Thiobacillus thioparus are added, the contents are mixed and the process is further conducted at a temperature of 3 to $60^{\circ} \mathrm{C}$ and $\mathrm{pH}=5-9$, from the resulting watercarbon mixture, biofuels are separated by settling, separation, distillation or demulsification.

The eichornia plant, which is offered as the main raw material for biofuels production, can reproduce vegetatively in Russia at temperatures above $16^{\circ} \mathrm{C}$. In the South of the country, vegetation in open water areas lasts up to 9 months, in the waters of the middle zone and Northern regions-from 4 to 7 months. Short-term cold spells up to $6^{\circ} \mathrm{C}$ the plant successfully tolerates in partially protected reservoirs from the wind. Eichornia has proven itself as an effective water purifier from various pollutants: petroleum products, phenol, phosphates, sulfates, amines, surfactants, fats, etc. In the middle and Northern regions, it is cultivated by seedlings, stored in a warm room in winter. 


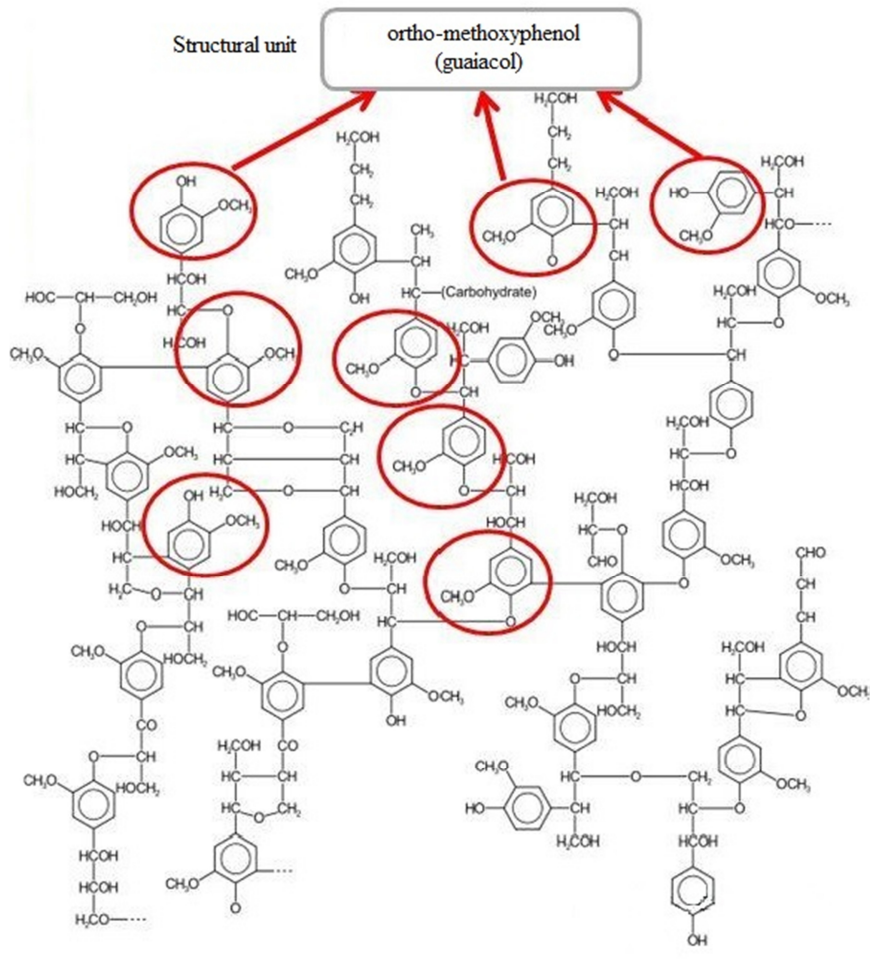

Fig. 2. Structure of lignin.

This plant has an extremely high ability to reproduce, which in 30 days can form more than 400 vegetative processes. One hectare of water surface hosting eichornia saves up to 810 hectares of land. Each hectare of settling ponds during the summer season can produce from 25 to 500 tons of green mass, which approximately $60 \%$ includes fiber, protein, fat, amino acids, potassium, phosphorus, calcium, etc. With an eichornia yield of $400 \mathrm{t} / \mathrm{ha}$, one hectare of water surface can on average replace 6.6 ha of arable land on which sorghum is grown, with an average sorghum yield of $60 \mathrm{t} / \mathrm{ha}$. The use of eichornia as a raw material for biofuels will expand interest in its high use as a cheap and affordable water purifier. It is also possible to use peat, which is due to its availability, cheapness and good ability to microbiological processing into a gaseous or liquid fuel. Lignin, having a unique chemical structure (figure 2), is a large-tonnage waste of pulp and paper plants, large reserves of it have been accumulated and it is easily subjected to microbiological processing.

The selected types of microorganisms are available and can be successfully used to produce biofuels from organic raw materials. The process of obtaining biofuels includes two stages, which differ mainly in the microorganisms used. Microorganisms contained in the fermented slurry or active digester sludge contribute to an increase in the output of methane and the light fraction of liquid hydrocarbons. Microorganisms of the second stage, namely Thiobacillus aquaesulis and Thiobacillus thioparus, used in any ratio, are effective in recovering $\mathrm{CO}_{2}$ to $\mathrm{CH}_{4}$ in the presence of hydrogen-donor substances and the destruction of organic high-molecular substances.

Waste from wood processing, in particular lignin, and waste from sugar beet cultivation and processing are recommended as catalysts for methane production. Their choice is determined by experimentally established efficiency. Other substances containing cellulose, its derivatives, glucose, and fructose may be used. As microorganisms, at the first stage, methanogenic cultures are used, obtained by fermentation of slurry, stomach contents of 
animals, mainly cattle and active digester sludge. The consumption of the fermented substrate is experimentally justified as equal from 10 to $30 \%$ of the dry mass of the raw material. As a culture composition, a phosphate-chloride-carbonate buffer containing $\mathrm{g} / \mathrm{l}$ is used: $\mathrm{K}_{2} \mathrm{HPO}_{4}-0.02 ;\left(\mathrm{NH}_{4}\right) \mathrm{CO}_{3}-0.01 ; \mathrm{MgCl}_{2}-0.2 ; \mathrm{CaCl}_{2}-0.4 ; \mathrm{NH}_{4} \mathrm{OH}-0.04$. Using $\mathrm{NH}_{4} \mathrm{OH}$ or $\mathrm{HNO}_{3}$, a pH of 7.3-7.7 is set. Fermented substrate consists of $10-30 \%$ of the mass of slurry and animals stomach contents and/or up to $70 \%$ of the digester sludge. The process of obtaining methane is recommended to be conducted at a temperature of $15-70^{\circ} \mathrm{C}$, preferably $40-50^{\circ} \mathrm{C}$, since in this interval the process of output of methane and the time of processing of raw materials is most effective.

A liquid hydrocarbon, such as kerosene, is added to absorb the resulting liquid biofuel. The resulting carbon dioxide is separated from methane by passing the resulting gas medium through sorbents, a $\mathrm{CO} 2$ - absorbing solution containing a culture liquid, or by using a membrane that passes methane but retains carbon dioxide. The return of carbon dioxide back to the reactor, the presence of hydrogen-donor substances and the abovementioned microorganisms in the reactor ensure an increase of output of methane due to the reduction of carbon dioxide.

The resulting methane is collected, its volume is measured, and its mass is calculated. Approximately at $50-60 \%$ of the output of methane on the dry raw material mass is transferred to the second stage. Transfer to the second stage can be accompanied by cooling of the reactor up to $5-10^{\circ} \mathrm{C}$ with subsequent addition of hydrogen donor substances: nitric, sulfuric, acetic, sulfamic acids, amines, hydrides, powders of active metals, etc. Continue the process at $3-60^{\circ} \mathrm{C}$, preferably at $15-20^{\circ} \mathrm{C}$ and $\mathrm{pH}=5-9$. The duration of both stages of the process is from 7 to 20 days. From the water-carbon mixture obtained in the reactor, biofuels are separated by settling, distillation, separation or demulsification, using one or a combination of several methods.

The main operations performed when implementing the method are:

- grinding of eichornia and peat raw materials to the size of $0.4-0.5 \mathrm{~cm}$; loading of initial hydrocarbon, crushed raw materials, methanogenic liquid with a culture medium based on a phosphate-chloride-carbonate buffer into the reactor.

- introduction of catalysts for the intensification of the biogas extraction process, which are wood processing waste containing cellulose, humates, lignin, etc. and / or sugar production waste, such as beet residues, substandard molasses; purging the reactor with nitrogen or air and five-minute mixing of the reaction mass;

- maintaining anaerobic or aerobic conditions in the reactor at a temperature of $15-70^{\circ} \mathrm{C}$, periodically mixing the contents of the reactor after 2-3 hours; selecting synthesized methane, releasing carbon dioxide and leaving or returning it to the reactor; adding hydrogen donor substances to the reactor (humic compounds, acids, amines, hydrides, metal powders, etc.) in a mixture or separately; introducing microorganisms Thiobacillus aquaesulis and Thiobacillus thioparus with a culture medium based on a phosphatechloride-carbonate buffer into the reactor, mixing the contents of the reactor;

- maintaining the process conditions: temperature $2-60^{\circ} \mathrm{C}, \mathrm{pH}=5-9$; separation of the liquid fraction of hydrocarbons by settling, separation, distillation or demulsification.

These data show that the proposed method expands the raw material base by using the high-yielding eichornia plant, while increasing the output of biofuels from 87 to $96 \%$, including methane from 30 to $75 \%$. In the liquid fraction of hydrocarbons, the content of the aromatic component is almost doubled, which makes it possible to obtain gasoline with an increased octane number. The content of sulfur in the liquid fraction is reduced by about an order of magnitude, and phenol by 5 times, which reduces the corrosion activity and toxicity of biofuels, respectively.

As a result, the implementation of these measures expands the raw material base for obtaining biofuels, increases its output, improves the quality of biofuels by grinding the 
initial row materials by microorganisms in the presence of compounds that are hydrogen donors, using the eichornia plant and its mixtures with peat, lignin and fermented slurry, animal stomach contents and active digester sludge, which include methanogenic microorganisms with a culture medium based on a phosphate-chloride-carbonate buffer, as well as catalysts for the intensification of the biogas extraction process in the form of wood processing waste containing humates, cellulose and / or sugar production waste, and the process is carried out at the beginning at a temperature of 15 to $70^{\circ} \mathrm{C}$ in anaerobic or aerobic conditions, selecting synthesized methane and leaving resulting carbon dioxide in the reactor, adding hydrogen donor substances, humic compounds, microorganisms of the species Thiobacillus aquaesulis and Thiobacillus thioparus, the content of the reactor is mixed and the process is further conducted at a temperature of 3 to $60^{\circ} \mathrm{C}$ and a $\mathrm{pH}$ of $5-9$, from the resulting water-hydrocarbon mixture, the biofuels are separated by settling, separation and distillation.

\section{Conclusion}

The approaches to produce biofuels considered in the paper, when they are competent for their further modernization is modern significance, allowing to solve the economic issues of reducing the energy dependence of the economy on the market of hydrocarbons, and successfully resolve issues in regional energy supply, agricultural and industrial areas deprived of access to cheap oil. In the strategic plan, the proposed measures solve important economic and macroeconomic problems, since on the one hand, the development of alternative methods of energy production is an innovative sphere of production and stimulates the growth of national scientific and intellectual potential, on the other hand, the development of alternative energy significantly affects pricing in the World market of hydrocarbons, where at the moment the leading role is played not so much by economic, but by political factors and motives, which for their implementation cloaked by economic and financial reasons and without high-quality competition have the opportunity to use the mechanism of price collusion, while alternative energy is able to overcome these restrictions.

However, the use of microorganisms to produce biofuels is not wide spread, it is constrained by a number of shortcomings in the technological process that require further research and solutions. The main ones are: high aggressive production environment, which requires the use of special equipment and devices to protect the environment; the need to develop technology for processing non-decomposed waste to obtain a product quality comparable to classic fuel; the need to develop a method for cleaning atmospheric emissions that ensure normal working conditions for service personnel and the population of nearby areas. Thus, the use of these methods to eliminate these shortcomings will significantly expand the production of biofuels from wood processing and agricultural waste.

\section{References}

1. K. Jayanthakumaran, R. Verma, Y. Liu. Energy Policy 42, 450-460 (2012) DOI: 10.1016/j.enpol.2011.12.010

2. E. Shafiei, B. Davidsdottir, R. Fazeli, H. Stefansson, E. Asgeirsson, Energy Policy 114, 431-443 (2018) DOI: 10.1016/j.enpol.2017.12.034

3. Q. Wang, X. Chen, A. Jha, H. Rogers, Renewable and Sustainable Energy Reviews 30, 1-28 (2014) DOI: 10.1016/j.rser.2013.08.065 
4. M. Jamil, F. Ahmad, Y. Jeon, Renewable and Sustainable Energy Reviews 55, 11811194 (2016) DOI: 10.1016/j.rser.2015.05.087

5. J. Reimer, X. Zheng, Renewable and Sustainable Energy Reviews 77, 945-954 (2017) DOI: 10.1016/j.rser.2016.12.036

6. B. Henderson, A. Golub, D. Pambudi, O. Cacho, P. Gerber, Mitigation and Adaptation Strategies for Global Change 23(3), 349-369 (2018) DOI: 10.1007/s11027-017-9737-0.

7. D. Criekemans, Lecture Notes in Energy 61, 37-73 (2018) DOI: 10.1007/978-3-31967855-92

8. C. Hunsberger, L. German, A. Goetz, Energy Policy 108, 791-805 (2017) DOI: 10.1016/j.enpol.2017.04.017

9. N. Gaurav, S. Sivasankari, G. Kiran, A. Ninawe, J. Selvin, Renewable and Sustainable Energy Reviews 73, 205-214 (2017) DOI: 10.1016/j.rser.2017.01.070

10. E. Gawel, N. Pannicke, N. Hagemann, Sustainability (Switzerland) 11(11), 3005 (2019) DOI: 10.3390/su11113005

11. A. Shelton, J.-Z. Zhao, R. Roush, Annual Review of Entomology 47, 845-881 (2002) DOI: 10.1146/annurev.ento.47.091201.145309

12. C. Snyder, T. Bruulsema, T. Jensen, P. Fixen, Agriculture, Ecosystems and Environment 133(3-4), 247-266 (2009) DOI: 10.1016/j.agee.2009.04.021

13. D. Bajwa, T. Peterson, N. Sharma, J. Shojaeiarani, S. Bajwa, Renewable and Sustainable Energy Reviews 96, 296-305 (2018) DOI: 10.1016/j.rser.2018.07.040

14. L. Cutz, P. Haro, D. Santana, F. Johnsson, Renewable and Sustainable Energy Reviews 58, 1411-1431 (2016) DOI: 10.1016/j.rser.2015.12.322 